\title{
Ergonomi Pembagian Zona Kerja Terbatas Pada Gerobak Streetfood di Kota Yogyakarta
}

\author{
Bambang Pramono \\ Program Studi Desain Interior ISI Yogyakarta \\ Email: bambang.pramono@isi.ac.id
}

\begin{abstract}
Abstrak
Kuliner kaki lima kerap menjadi pilihan jajan yang murah dan beragam serta mudah ditemui di sudut-sudut kota, hampir setiap hari kuliner kaki lima dapat dicari mulai berjualan dari pagi, siang, hingga malam. Para pedagang tersebut ada yang berjualan menggunakan gerobak baik yang di dorong maupun yang di pikul, dengan menggunakan sepeda, bahkan ada pula yang menambah tenda untuk tempat makan konsumennya. Desain gerobak street food beserta aktifitas perdagangan yang terjadi didalamnya seharusnya mempertimbangkan aspek ergonomi serta antropometri penggunganya. Penerapan ilmu ergonomi pada desain gerobak street food secara tidak langsung mempengaruhi produktivitas kerja manusia dengan pengelolaan zona kerja pada dapur terbatas di gerobak steetfood.
\end{abstract}

Kata kunci: ergonomi, zona kerja, dapur, kuliner kaki lima

\begin{abstract}
Street food is often a cheap and varied choice of snacks and is easily found in the corners of the city, almost every day culinary can be searched starting selling from morning, noon, until evening. Some of the traders sell using carts that are either pushed or carried, using bicycles, and some even add tents for their consumers to eat. The design of street food carts and the trading activities that occur in them should consider the ergonomic aspects and anthropometry of the users. The application of ergonomics to the design of street food carts indirectly affects the productivity of human work by managing work zones in limited kitchens on steet food carts.
\end{abstract}

Keywords: ergonomic, work station, kitchen, streetfood

\section{Pendahuluan}

Sektor kuliner di Indonesia memiliki potensi ekonomi dan pariwisata yang besar bagi daerah, potensi sektor kuliner juga didukung oleh kekayaan kulinary khas Indonesia yang mencapai 5.300 kuliner tradisional yang tersebar lebih dari 17.000 pulau. Keanekaragaman kuliner khas Indonesia menjadi daya tarik tersendiri bagi wisatawan sehingga berdampak pada sektor pariwisata, kuliner menjadi sebuah identitas suatu kota atau daerah yang secara tidak langsung telah mempromosikan suatu kota dengan destinasi wisata kulinernya ke wisatawan, baik wisatawan mancanegara maupun wisatawan nusantara. Salah satu destinasi unggulan wisata kuliner di Indonesia adalah kota Yogyakarta, beragam kuliner tradisional dengan jenis yang beragam serta cara penyajianya yang unik mulai dari yang sederhana yang dapat dijumpai di pinggir jalanan hingga kuliner tradisional berstandar internasional dapat ditemukan di Yogyakarta. Streetfood umum dikenal di Indonesia sebagai jajanan kaki lima yang menjual makanan atau minuman yang siap santap yang dijual di jalanan atau area publik oleh penjaja atau penjual keliling, kios atau tenda yang mudah dibereskan. Kuliner kaki lima kerap menjadi pilihan jajan yang murah dan beragam serta mudah ditemui di sudut-sudut kota Yogyakarta, hampir setiap hari kuliner kaki lima dapat dicari mulai berjualan dari pagi, siang, hingga malam.

Gerobak jajanan kaki lima biasanya memiliki bentuk dan rancang bangun yang hampir sama meskipun terdapat perbedaan khusus sesuai dengan jenis makanan yang dijual. Bentuk gerobak 
kaki lima mirip seperti lemari portable untuk memamerkan atau menyimpan bahan baku makanan, beberapa gerobak dilengkapi dengan kompor kecil berbahan gas elpiji, tungku pemanas, anglo, panci besar, wajan penggorengan sampai gril pemanggang berbahan bakar arang. Gerobakgerobak ini biasanya menggunakan material kayu atau logam lengkap dengan jendela kaca serta lapisan alumunium atau seng. Zona kerja dapur terbatas pada gerobak kaki lima didesain dengan mempertimbangkan kebutuhan pada alur sirkulasi kerja penggunanya, proses masak terbagi menjadi beberapa bagian kegiatan yaitu menyiapkan bahan, membersihkan, meracik, memasak serta menyajikan. Secara garis besar proses memasak di dapur dikelompokan dalam tiga zona aktivitas yaitu zona penyimpanan, zona racik dan zona penyajian.

Desain gerobak street food beserta aktifitas perdagangan yang terjadi didalamnya seharusnya mempertimbangkan aspek ergonomi serta antropometri penggunganya. Penerapan ilmu ergonomi pada desain gerobak street food secara tidak langsung mempengaruhi produktivitas kerja manusia, (Nurmianto, Eko, 2004) dalam bukunya Ergonomi : Konsep Dasar dan Aplikasinya menggungkapkan bahwa banyak penerapan ilmu ergonomi hanya berdasarkan "common sense" atau sesuatu yang sudah biasa terjadi, dan hal ini menjadi keuntungan besar bagi penggunanya walaupaun dengan menggunakan satu prinsip yang sederhana seperti membagi zona kerja pada dapur terbatas. Dari pengamatan serta survey awal pada beberapa pedagang street food dengan menggunakan sarana gerobak sebagai alat bantu dagangnya menemukan fakta bahwa belum adanya kesadaran akan faktor-faktor ergonomis yang membantu produktivitas kerja pedagang streetfood.

\section{Metode}

Pada penelitian ini digunakan metode studi kasus ysng dilkukan dengan cara meneliti suatu permasalahan melalui studi kasus gerobak jajanan kaki lima yang ada di kota Yogyakarta. Penelitian studi kasus merupakan penelitian yang dilakukan dengan cara meneliti suatu permasalahan melalui satu kasus yang terdiri dari satu unit tunggal. Unit tunggal dalam hal ini dapat berarti satu pedagang streetfood yang mewakili jenis pedagang lainnya yang sejenis daganganya. Dari sisi cakupan wilayah kajiannya, Studi Kasus terbatas pada wilayah yang sempit (mikro), karena mengkaji perilaku pada tingkat individu, kelompok, lembaga dan organisasi. Kasusnya pun dibatasi pada pada jenis kasus tertentu, di tempat atau lokus tertentu, dan dalam waktu tertentu. Karena wilayah cakupannya sempit, penelitian Studi Kasus tidak dimaksudkan untuk mengambil kesimpulan secara umum atau memperoleh generalisasi, karena itu tidak memerlukan populasi dan sampel. Namun demikian, untuk kepentingan penelitian Studi Kasus diharapkan dapat menghasilkan temuan yang dapat berlaku di tempat lain jika ciri-ciri dan kondisinya sama atau mirip dengan tempat di mana penelitian dilakukan, yang lazim disebut sebagai transferabilitas (Rahardjo, Mudjia, 2017).

Penelitian ini berusaha mengkaji aspek ergonomi pada grobak street food yang ada di kota Yogyakarta dengan mengambil sample objek beberapa pedagang jajanan kaki lima ada 11 sample pedagang streetfood yang di ulas dalam penelitian ini, diantara pedagang bakmi jawa, ,martabak, bakwan kawi, ketoprak, thai tea, kopi keliling, angkringan, seblak, mie ayam, batagor, roti bakar, sate, dan tahu gimbal. Dari penelitian ini diharapakan dapat membuka wawasan bagaimana keilmuan desain khususnya dalam kajian ergonomi berperan dalam mengatasi permasalahan dapur pada lahan terbatas dengan penerapan pembagian zona kerja yang sederhana.

\section{Pembahasan}

Pola pedagang streetfood dengan desain gerobak dagangannya dapat diidentifikasi berdasarkan cara berjualanya yaitu dengan statis (menetap) atau dengan dinamis (berkeliling). Dari beberapa sample pedagang streetfood di kota Yogyakarta dilakukan pengumpulan data berupa profil 
pedagang, peralatan yang digunakan, proses penyajian, bahan atau material serta lingkungan kerja pedagang.

Ergonomi merupakan multidisiplin yang terdiri dari perpaduan keilmuan psikologi, anatomi dan kedokteran. Sedangkan fokus kajian ergonomi mancakup biomekanik, kinesiologi, fisiologi kerja, dan antropometri. Pendekatan biomekanik pada desain tempat kerja yang utama mempertimbangkan kemampuan pekerja, tuntutan tugas dan peralatan yang terintegrasi. Prinsip kinesiologi harus diterapkan guna mencegah pergerakan yang tidak sesuai, sedangkan fisiologis kerja menggambarkan reaksi fisiologis pekerja terhadap tuntutan kerja dan memeliharanyya pada batasan yang aman. Antropometri berfokus pada dimensi tempat kerja peralatan dan material yang digunakan. (Pulat, Bubur, Mustafa, 1992). Di dalam ergonomi dibutuhkan studi tentang sistem dimana manusia, fasilitas kerja dan

lingkungannya saling berinteraksi dengan tujuan utama yaitu menyesuaikan suasana kerja dengan manusianya (Nurmianto, 2004). Apabila ingin meningkatkan kemampuan manusia untuk melakukan tugas, maka beberapa hal di sekitar lingkungan alam manusia seperti peralatan, lingkungan fisik, posisi gerak (kerja) perlu direvisi atau dimodifikasi atau redesain atau didesain disesuaikan dengan kemampuan dan keterbatasan manusia. Dengan kemampuan tubuh yang meningkat secara optimal, maka tugas kerja yang dapat diselesaikan juga akan meningkat. Sebaliknya, apabila lingkungan alam sekitar termasuk peralatan yang tidak sesuai dengan kemampuan alamiah tubuh manusia, maka akan boros penggunaan energi dalam tubuh, cepat lelah, hasil tidak optimal bahkan mencelakakan. Keilmuan ergonomi dalam mengakaji dapur dibutuhkan untuk merancang tempat kerja (workplace) serta pola kerja penggunanya, proses dan produk yang dapat digunakan oleh manusia agar mereka dapat bekerja dengan mudah, efisien, dan aman. Dengan demikian, manusia sebagai pengguna menjadi pusat seluruh aktivitas perancangan/desain peralatan kerja dapur.

Zona kerja pada dapur sangat dipengaruhi oleh pola gerak serta dimensi tubuh penggunanya yang dapat dibagi menjadi dua jenis, yakni zona kerja statis dan zona kerja dinamis. Dimensi tubuh manusia yang mempengaruhi perancangan ruang Interior terdiri dari dua jenis yaitu struktural dan fungsional. Dimensi struktural disebut sebagai dimensi static, yang mencakup pengukuran atas bagian-bagian tubuh yaitu kepala, batang tubuh dan anggota badan lainnya pada posisi standar. Dimensi fungsional disebut sebagai dimensi dinamik yaitu pengukuran yang diambil pada posisiposisi kerja atau selama pergerakan yang dibutuhkan oleh suatu pekerjaan dalam persepsi kenyamanan (Panero, Julius, and Martin Zelnik., 2003)
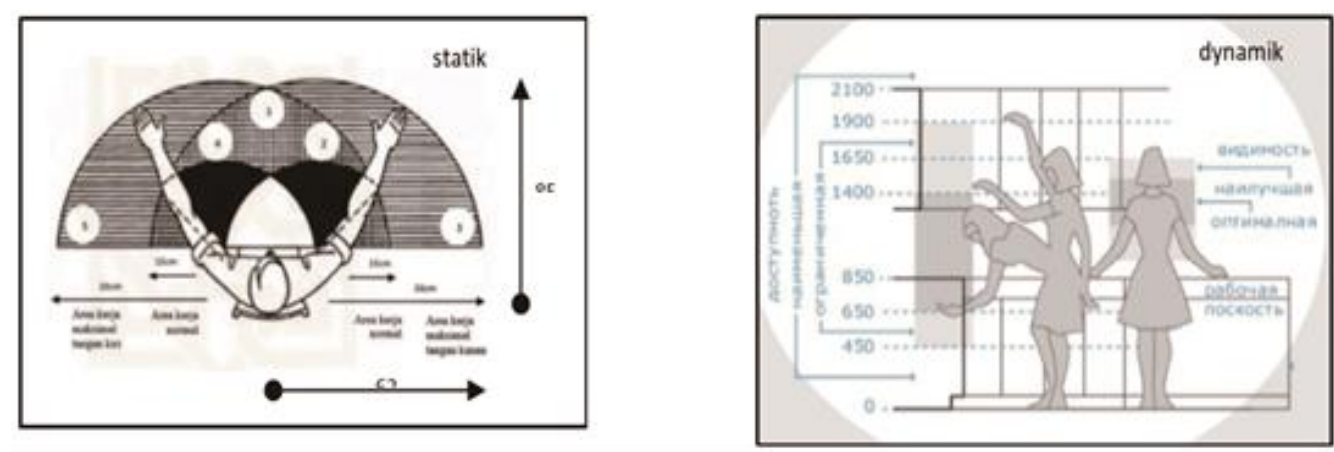

Gambar 1. Zona Kerja Dapur Statis dan Dinamis Sumber : (Suvatno Sastrowinoto, 1985) 

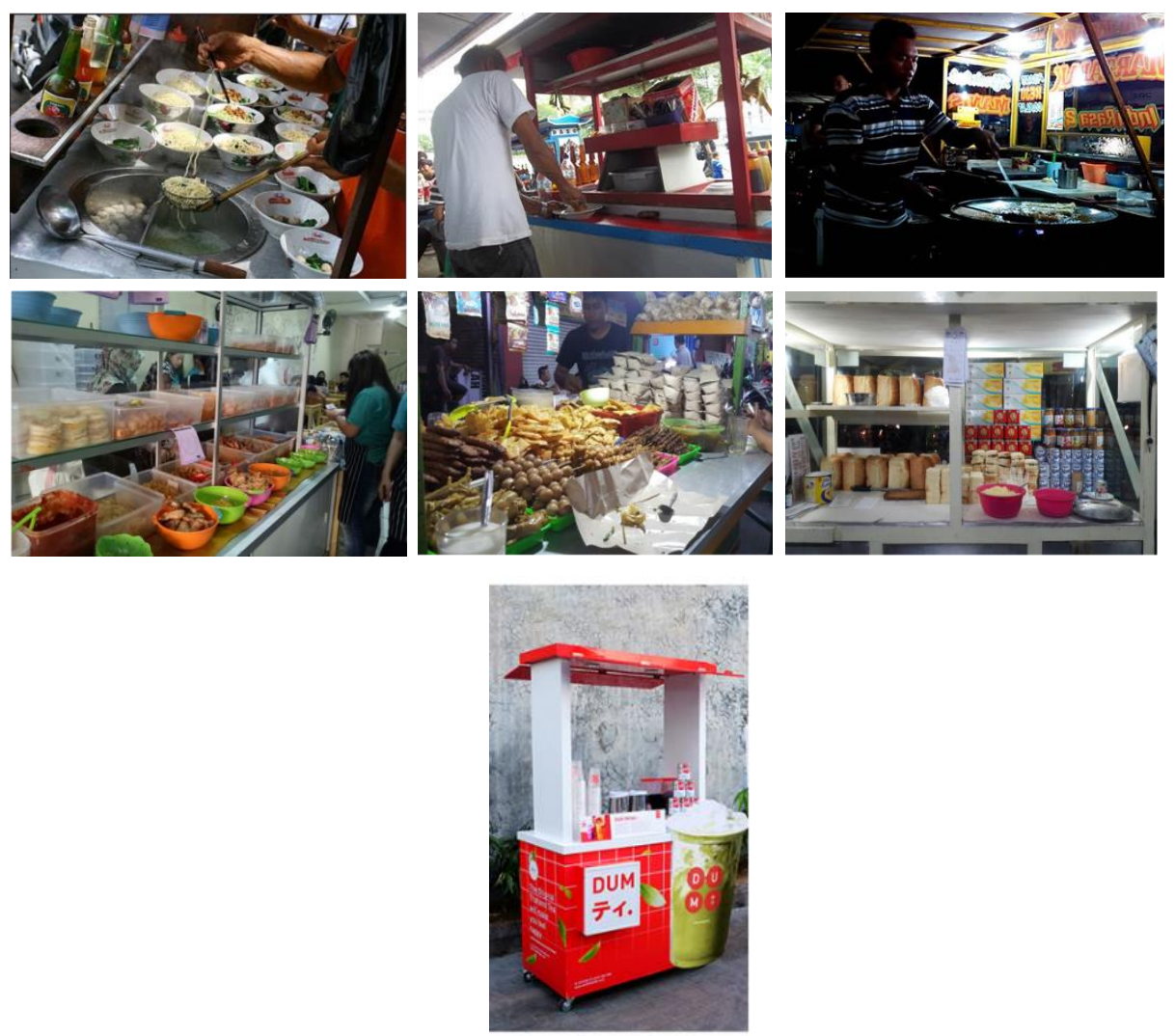

Gambar 2. Gerobak Streetfood Statis Sumber : (Dokumen Penulis,2019)
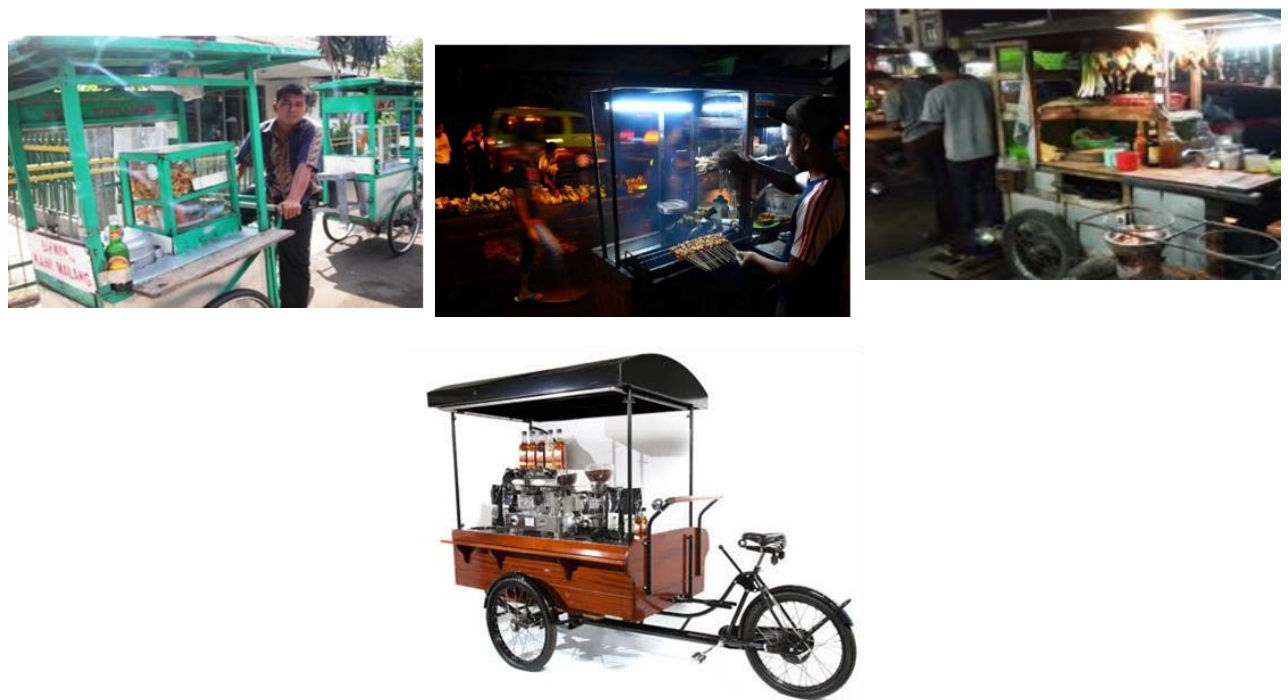

Gambar 3. Grobak Streetfood Dinamis Sumber : (Dokumen Penulis, 2019) 
Tabel 1. Analisa dan Desain Gerobak Streetfood Statis Sumber : (Dokumen Pribadi,2019)

\begin{tabular}{|c|c|}
\hline Martabak Kub & Pembagian zona kerja meliputi area racik, area masak, penataan topping, \\
\hline Ketoptak & $\begin{array}{c}\text { Pembagian zona kerja meliputi area penyimpanan, area racik, area masak, } \\
\text { dan area penyajian }\end{array}$ \\
\hline Mie Ayam & Pembagian zona kerja meliputi area persiapan, area masak, area racik, dan area \\
\hline Thai Tea & $\begin{array}{c}\text { Pembagian zona kerja meliputi area area penyimpanan, area display, area racik, } \\
\text { area dan packaging. }\end{array}$ \\
\hline Seblak & $\begin{array}{c}\text { Pembagian zona kerja meliputi area servis (order), area penyimpanan, area racik, } \\
\text { area masak, dan area penyajian }\end{array}$ \\
\hline
\end{tabular}




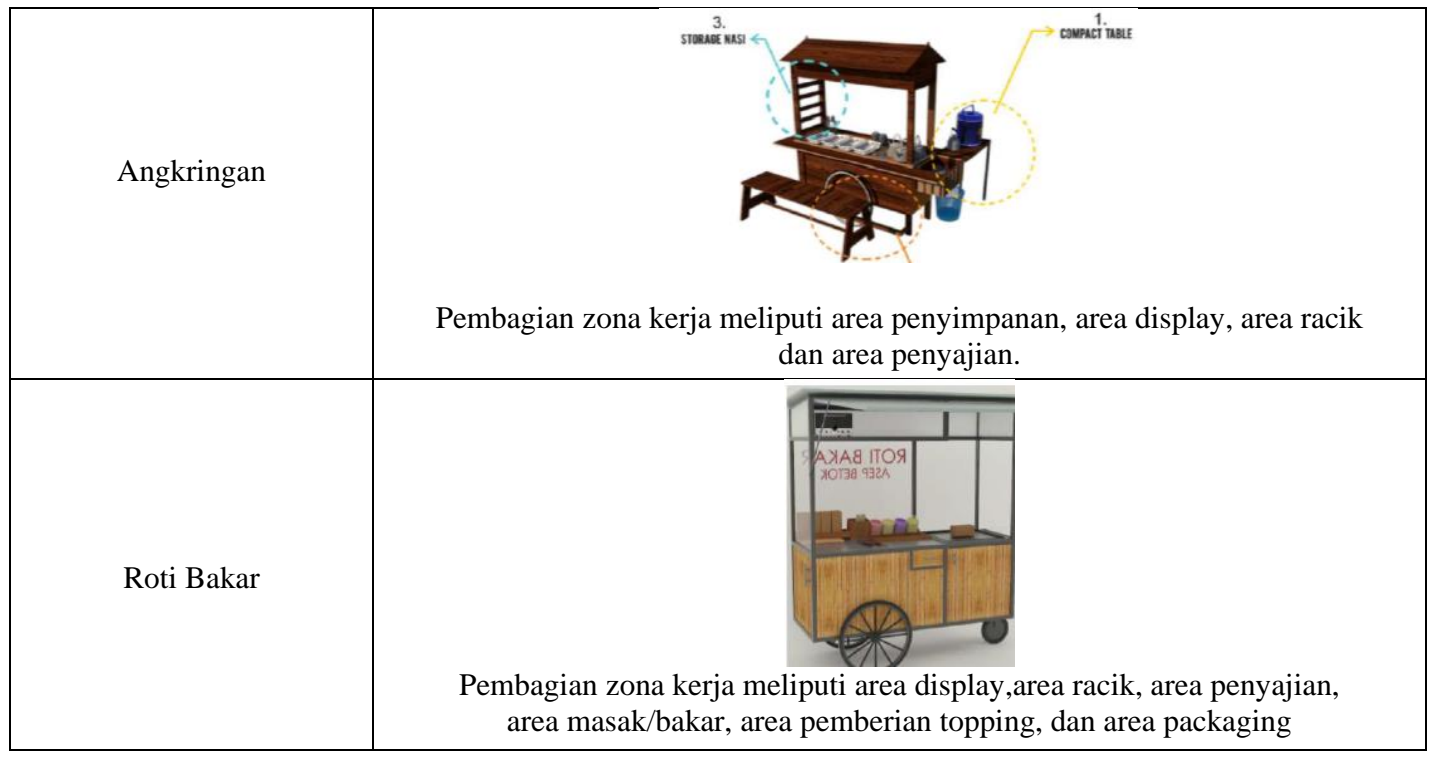

Tabel 2. Analisa dan Desain Gerobak Steetfood Dinamis Sumber : (Dokumen Penulis, 2019)

Sate Ayam $\quad$ Pembagian zona kerja meliputi area persiapan bumbu, area pembakaran,




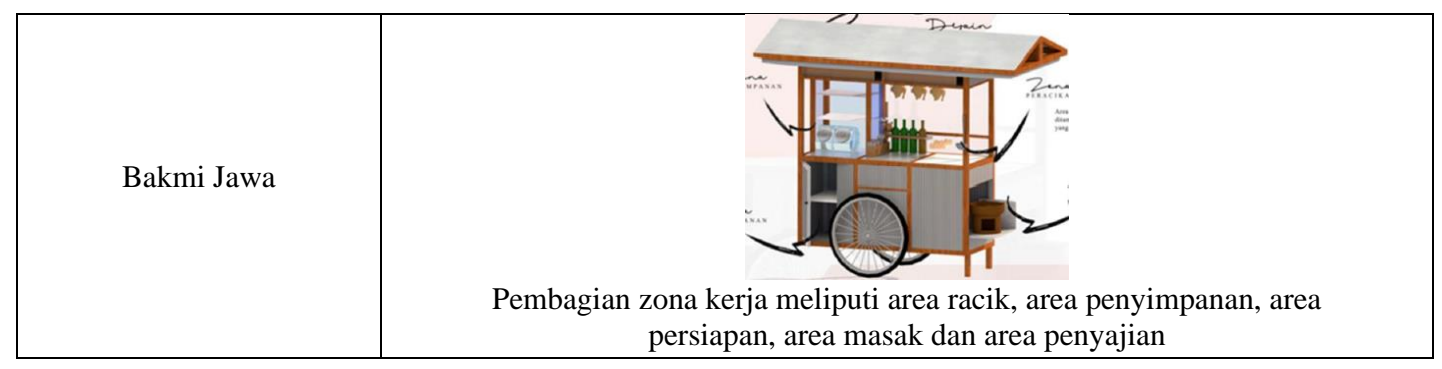

\section{Simpulan}

Indonesia kaya akan kuliner jajanan kaki lima, hampir di setiap daerah memiliki ciri khas jajanan masing-masing. Begitu pula dengan Yogyakarta sebagai kota pelajar, pusat budaya serta pariwisata menjadikannya salah satu kota dengan kuliner kaki lima terbanyak. Jajanan kaki lima tidak semata soal makanan dan minuman yang mudah dikonsumsi, lebih dari itu cita rasa serta segi entertain dalam hal menyajikan makanan dan minuman yang sederhana menjadi daya tarik khusus bagi pelanggan. Begitu mudah jajanan kaki lima ditemui disudut kota Yogyakarta, diwarungwarung, kios, toko, gerobak, tak terkecuali gelaran pedagang kaki lima di pinggir jalan raya hingga di gang sempit dapat ditemui. Dari sekian banyak pedagang kaki lima yang menjajakan bisnis makanan dan minuman tersebut dapat dibedakan menjadi dua kategori tipe pedagang kaki lima, pertama pedagang kaki lima dengan tipe "mangkal" biasanya lapak dagangan statis atau menetap di suatu lokasi, dan kedua pedagang dengan tipe " berkeliling" biasanya lapak dagangan lebih mudah dibawa dan fleksibel. Dari kedua pola tersebut tidak luput dari peran gerobak yang memiliki fungsi sebagai dapur mini untuk meracik daganganya agar dapat dinikmati oleh pelanggan.

Jajanan kaki lima atau streetfood menjadi tulang punggung perekonomian rakyat, selain menjual makanan atau minuman dengan harga yang terjangkau perannya juga penting dalam melestarikan kuliner tradisional suatu daerah. Steetfood memiliki peran penting dalam perkembangan kuliner nasional, melalui pedagang streetfood kuliner nusantara menjadi lebih beragam dan akan terus terpelihara, selain itu streetfood juga berperan penting di sektor kewirausahaan dan enterpreneurship karena melahirkan pedagang yang mampu berdikari bahkan sampai ke taraf global. Kuliner kaki lima adalah makanan yang apa adanya, diolah dengan sederhana dan disempurnakan oleh tradisi bertahun-tahun sehingga keberadaanya tidak semata memunuhi kebutuhan lapar dan haus, namun juga berkaitan dengan bisnis, mata pencaharian serta warisan budaya.

Berdasarkan dari hasil analisis dari beberapa pedang sreetfood umumnya menunjukkan terdapat beberapa faktor ergomis yang mendukung produktiviats pedagang, faktor-faktor tersebut didapatkan setelah melakukan survey dan pengamatan yang mendalam atas sample yang dilakukan terhadap 11 pedagang streetfood yang dipilih berdasarkan purpose sampling. Faktor-faktor ergonomis tersebut didasari atas analisa terhadap zona kerjanya yang meliputi: profil user, perlatan yang digunakan, material, lingkungan temapt berjualan, serta proses pengolahan bahan jajanan.

\section{Daftar Pustaka}

Kurniawidjaja, L.M,. (2010). Teori dan Aplikasi Kesehatan Kerja. Jakarta: Universitas Indonesia. 
Lintas Ruang: Jurnal Pengetahuan \& Perancangan Desain Interior | Vol 9.No 1Th. 2021|Hal 37- 44

Nurmianto, Eko. (2004). Ergonomi : Konsep Dasar dan Aplikasinya. Surabaya: Guna Widya.

Panero, Julius, and Martin Zelnik. (2003). Dimensi Manusia \& Ruang Interior. Jakarta: Erlangga.

Pulat, Bubur, Mustafa. (1992). Fundamental of Industrial Ergonomic-Prentice hall international series in industrial and system engineering,. New Jersey: Engelwood Cliffs.

Rahardjo, Mudjia. (2017). Studi Kasus Dalam Penelitian Kualitatif : Konsep dan Prosedurnya. Malang: Universitas Islam Negeri Maulana Malik Ibrahim. 